\title{
Mechanisms of anti-proliferative effect of JTE-522, a selective cyclooxygenase- 2 inhibitor, on human liver cancer cells
}

\author{
TAKAKAZU NAGAHARA, JUN-ICHI OKANO and YOSHIKAZU MURAWAKI \\ Second Department of Internal Medicine, Tottori University School of Medicine, \\ 36-1 Nishi-cho, Yonago, Tottori 683-8504, Japan
}

Received June 26, 2007; Accepted August 8, 2007

\begin{abstract}
Selective cyclooxygenase-2 (COX-2) inhibitors have been demonstrated to inhibit the proliferation of a variety of cancer cells including hepatocellular carcinoma (HCC). We sought to explore the mechanisms by which JTE-522, a selective COX-2 inhibitor, suppressed the growth of human HCC cells. HCC cells (HepG2, HLF, huH1, Huh7, and PLC/PRF/5 cells) did not express COX-2 at either the mRNA or protein level. Prostaglandin E2 (PGE2) levels in medium were not significantly modulated by the JTE-522 treatment. However, MTT assays disclosed that escalating doses (100 nM to $100 \mu \mathrm{M}$ ) of JTE-522 significantly inhibited the growth of all HCC cells in a dose- and time-dependent manner. JTE-522 induced cell cycle arrest at the G1 phase, which was in part mediated by downregulation of cyclin E. Hallmarks of apoptosis, including the sub-G1 fraction by flow cytometric analysis and nuclear fragmentation by nuclear staining, were not significantly induced after the JTE-522 treatment. In addition, JTE-522 enhanced the expression of peroxisome proliferator-activated receptor (PPAR)- $\gamma$ protein in HepG2 and PLC/PRF/5 cells. Our data demonstrate that JTE-522 inhibited the growth of HCC cells in a COX-2-independent manner, and that the growth inhibition was in part mediated by the cell cycle arrest and the upregulation of PPAR- $\gamma$ protein.
\end{abstract}

\section{Introduction}

Hepatocellular carcinoma (HCC) is one of the most common malignancies in the world and the third-leading cause of

Correspondence to: Dr Jun-ichi Okano, Second Department of Internal Medicine, Tottori University School of Medicine, 36-1 Nishi-cho, Yonago, Tottori 683-8504, Japan

E-mail: okanoj@hotmail.co.jp

Abbreviations: COX-2, cyclooxygenase-2; ERK, extracellular signal-regulated kinase; HCC, hepatocellular carcinoma; MTT, 3-(4,5-dimethylthiazol-2-yl)-2,5-diphenyltetrazolium bromide; PGE2, prostaglandin E2; PPAR, peroxisome proliferator-activated receptor; RT-PCR, reverse transcription-polymerase chain reaction

Key words: hepatocellular carcinoma, JTE-522, PPAR- $\gamma$, selective COX-2 inhibitor death from cancer (1). Most patients with HCC are complicated with liver cirrhosis commonly caused by infection with hepatitis $\mathrm{B}$ and $\mathrm{C}$ viruses (2). Although ablative therapies including arterial embolization, ethanol injection, and radiofrequency ablation (RFA) have been applied in patients with $\mathrm{HCC}$, therapeutic possibilities are limited, and the prognosis of these patients is still unsatisfactory, especially when diagnosed at advanced stages. Since the exact molecular mechanisms of hepatocarcinogenesis are still unclear, currently no efficient therapeutic compounds are available. Given the poor outcome of patients with HCC, there is an urgent need to develop novel therapeutic drugs targeting key molecules involved in hepatocarcinogenesis.

Cyclooxygenase-2 (COX-2) is an inducible enzyme converting arachidonic acid to prostaglandins (PGs). Several lines of evidence suggest that COX-2 may play a pivotal role in hepatocarcinogenesis. For example, $\mathrm{COX}-2$ is overexpressed in HCC (3), forced expression of COX-2 in HCC cells promotes cellular growth (4), selective COX-2 inhibitors suppress the proliferation of HCC cells (5-8), and selective COX-2 inhibitors prevent hepatocarcinogenesis in rodents (9). However, the exact mechanisms by which selective COX-2 inhibitors suppress the growth of HCC remain unsolved. In addition, it is controversial whether anti-proliferative action of the compounds is mediated via COX-2-dependent pathway or not (10), and the involvement of apoptosis remains the subject of debate $(5,11)$. The aim of our present study was to investigate the effects of JTE-522, a selective COX-2 inhibitor, on the growth of HCC cells, and to clarify the mechanisms of how JTE-522 induces cell death in HCC cells.

\section{Materials and methods}

Antibodies. Antibodies against human COX-1 and COX-2 were purchased from Cayman Chemical Company (Ann Arbor, MI, USA). Antibodies against the phosphorylated form of extracellular signal-regulated kinase (ERK)1/2 at the Thr202/ Tyr204 residues and $B$-actin were purchased from SigmaAldrich (St. Louis, MO, USA). Anti-caspase-3, phosphop38MAPK (Thr180/Tyr182), and phospho-c-Jun N-terminal kinase (JNK) (Thr183/Tyr185) antibodies were purchased from Cell Signaling Technology (Beverly, MA, USA). The phosphorylation-independent anti-ERK1/2 antibody was purchased from Stressgen Biotechnologies Corp. (Victoria, Canada). Antibodies against p27 (M-197), cyclin D1 (H-295), 
cyclin E (M-20), and PPAR- $\gamma$ (E-8) were from Santa Cruz Biotechnology Inc. (Santa Cruz, CA, USA). Secondary antimouse and anti-rabbit horseradish peroxidase antibodies were from GE Healthcare Ltd. (Buckinghamshire, UK).

Cell lines and JTE-522 treatment. Human liver cancer cells (HepG2, HLF, huH1, Huh7, and PLC/PRF/5) and human lung cancer cells (A549) were purchased from American Type Culture Collection (Manassas, VA, USA). The cells were cultivated in Dulbecco's modified Eagle's medium (DMEM) (Invitrogen Japan K.K., Tokyo, Japan), supplemented with $10 \%$ fetal bovine serum (FBS) and penicillin/streptomycin (Cosmo Bio Co., Ltd., Tokyo, Japan) at $37^{\circ} \mathrm{C}$ in a $5 \% \mathrm{CO}_{2}$ incubator. JTE-522 was kindly provided by Japan Tobacco, Inc. (Tokyo, Japan). JTE-522 (100 nM to $100 \mu \mathrm{M})$ dissolved in dimethyl sulfoxide (DMSO) (Wako Pure Chemical Industries, Ltd., Osaka, Japan) was added to culture medium with the final concentrations of DMSO at $0.1 \%$. Control samples always contained $0.1 \%$ DMSO.

Cell viability. Cell viability was assessed by modified 3-(4,5dimethylthiazol-2-yl)-2,5-diphenyltetrazolium bromide (MTT) assays (Cell counting kit-8, Dojindo Corp., Kumamoto, Japan) following the supplier's protocol. Briefly, cells were grown in 96-well plates at $37^{\circ} \mathrm{C}$ in a $5 \% \mathrm{CO}_{2}$ incubator and treated with compounds. After $10 \mu \mathrm{l}$ of reagent was added, the optical density (OD) 450 was measured by a microplate reader (Dade Behring, Deerfield, IL, USA) and percentage survival of the treated cells was calculated compared with untreated control cells containing $0.1 \%$ DMSO as a vehicle. The experiments were repeated 3 times and data were expressed as the mean $\pm \mathrm{SD}$.

Reverse transcription-polymerase chain reaction ( $R T-P C R)$. Total RNA was extracted from cells using Isogen (Nippon Gene Co., Ltd., Toyama, Japan), and RT-PCR was performed using the AccessQuick RT-PCR System (Promega, Madison, WI, USA) following the supplier's instructions. Briefly, $0.1 \mu \mathrm{g}$ of total RNA with $50 \mu \mathrm{l}$ of a reaction mixture, containing $1 \mu \mathrm{M}$ of sense and antisense primers, and 5 units of AMV reverse transcriptase, was reverse transcribed at $45^{\circ} \mathrm{C}$ for $45 \mathrm{~min}$. PCR reaction was carried out for 30 cycles (denaturing at $95^{\circ} \mathrm{C}$ for $30 \mathrm{sec}$, annealing at $54^{\circ} \mathrm{C}$ for COX-1, at $45^{\circ} \mathrm{C}$ for $\mathrm{COX}-2,55^{\circ} \mathrm{C}$ for PPAR- $\gamma$, and $48^{\circ} \mathrm{C}$ for $\beta$-actin, respectively, for $30 \mathrm{sec}$, and extension at $72^{\circ} \mathrm{C}$ for $1 \mathrm{~min}$ ). These cycles were followed by a $10-$ min extension at $72^{\circ} \mathrm{C}$. The PCR products were separated on a $1.5 \%$ agarose gel. The primers (Nippon EGT Co., Ltd, Toyama, Japan) were human COX-1 5'-TGC CCA GCT CCT GGC CCG CCG CTT-3' (sense) and 5'-GTG CAT CAA CAC AGG CGC CTC TTC-3' (antisense); human COX-2 5'-TGA AAC CCA CTC CAA ACA CAC AG-3' (sense) and 5'-TCA TCA GGC ACA GGA GGA AG-3' (antisense); human PPAR- $\gamma$ 5'-TCT CTC CGT AAT GGA AGA CC-3' (sense) and 5'-GCA TTA TGA GAC ATC CCC AC-3' (antisense); human 3 -actin 5'-GTT TGA GAC CTT CAA CAC CCC-3' (sense) and 5'-GTG GCC ATC TCC TGC TCG AAG TC-3' (antisense).

Total protein preparation and Western blotting. Total protein preparation and Western blotting were conducted as described previously (12). Briefly, cells were lysed in radioimmune precipitation (RIPA) buffer (Millipore Corp., MA, USA) supplemented with $1 \mathrm{mM}$ sodium orthovanadate, $1 \mathrm{mM}$ phenymethylsulfonyl fluoride (PMSF), and a protease inhibitor mixture tablet (Roche Diagnostics, Basel, Switzerland) for $10 \mathrm{~min}$ on ice. Total protein samples $(10 \mu \mathrm{g})$ were separated on a sodium lauryl sulfate (SDS)-polyacrylamide gel (PAGE) and transferred to a polyvinylidene difluoride (PVDF) membrane (Immobilon-P, Millipore Corp.). After the membranes were blocked in 5\% non-fat milk (Santa Cruz Biotechnology

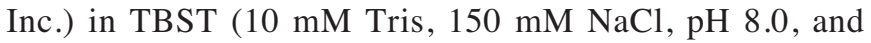
$0.1 \%$ Tween-20) for $1 \mathrm{~h}$ at room temperature, they were probed with primary antibodies overnight at $4^{\circ} \mathrm{C}$, washed 3 times in TBST, incubated with anti-mouse or anti-rabbit horseradish peroxidase (HRP) antibody in TBST for $1 \mathrm{~h}$ at room temperature. The signals were visualized by a chemiluminescence solution (ECL, GE Healthcare Ltd.). The signals were quantified by scanning densitometry software (Quantity One Basic, Bio-Rad Laboratories, Inc., Hercules, CA, USA).

PGE2 immunoassay. PGE2 levels in culture medium were measured in triplicate by using the Prostaglandin E2 immunoassay kit (R\&D Systems, Inc., Minneapolis, MN, USA) following the manufacture's protocol.

Hoechst 33258 staining. Cells grown in 8-well slides (Nalgen Nunc International, Rochester, NY, USA) were fixed in methanol/acetic acid (3:1) solution for $15 \mathrm{~min}$, washed with phosphate-buffered saline (PBS) for 5 min 3 times, and stained with Hoechst 33258 solution (Sigma-Aldrich) for $20 \mathrm{~min}$ under light-protected conditions. The cells were observed under a fluorescent microscopy.

Flow cytometry. The cell pellets were washed with PBS containing $1 \%$ FBS, fixed in $70 \%$ ethanol, stained with $0.5 \mathrm{mg} /$ $\mathrm{ml}$ propidium iodide (Sigma) containing 3 Kunitz RNase (Nippon Gene Co., Ltd.). Flow cytometric analyses were performed with a flow cytometer (EPICS-XL, Beckman Coulter Inc., Miami, FL, USA).

Statistical analysis. Data were expressed as the mean \pm SD. The data of MTT and PGE2 assays were analyzed using the paired-t test to assess differences between experimental groups. Statistical significance was inferred at $\mathrm{p}<0.05$.

\section{Results}

Expression of COX-2 mRNA and protein in HCC cells. First, we evaluated the expressions of COX-1 and COX-2 at mRNA and protein levels in human HCC cells under serum-free and $10 \%$ serum conditions, because various growth factors in serum could enhance the expression of COX-2 (13). COX-1 was almost ubiquitously expressed in all HCC cells at both mRNA and protein levels independently of serum conditions. In contrast, no $\mathrm{HCC}$ cell line expressed $\mathrm{COX}-2$ at either the mRNA or protein level (Fig. 1A and B). In A549, lung cancer cells, we were able to detect COX-2 mRNA and protein at a serum-free condition, which were significantly enhanced after the treatment with vanadate, an established inducer of COX-2 (14), validating our experimental conditions. Thus, 

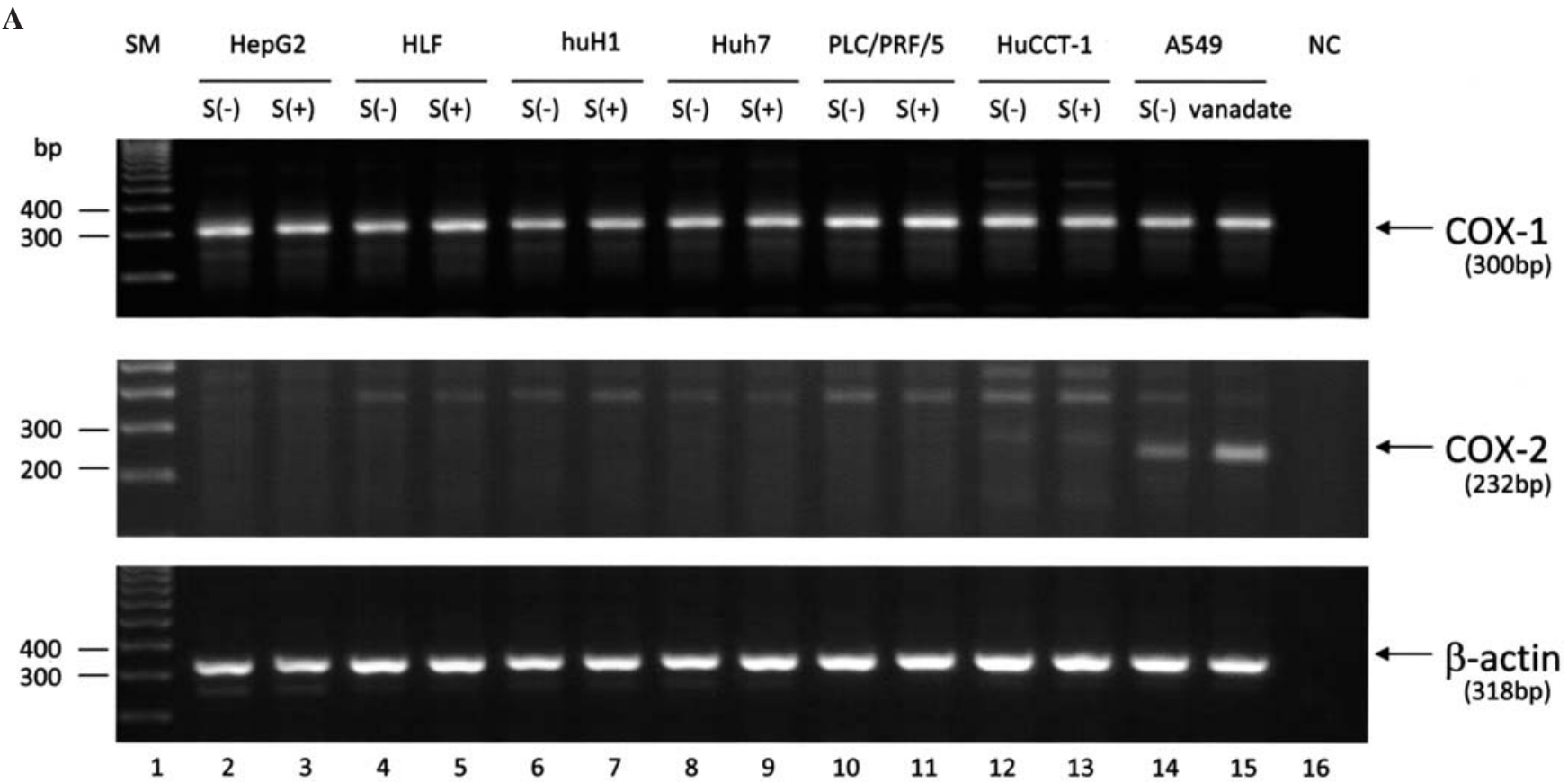

B

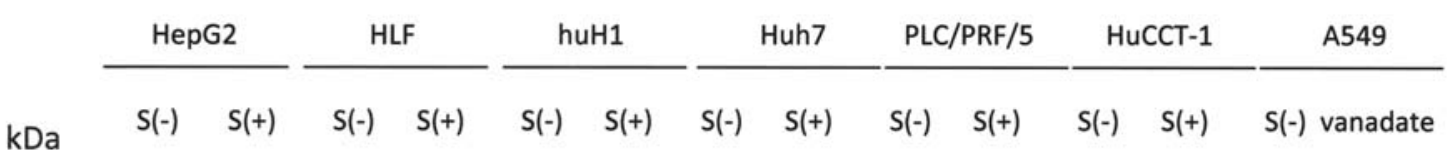
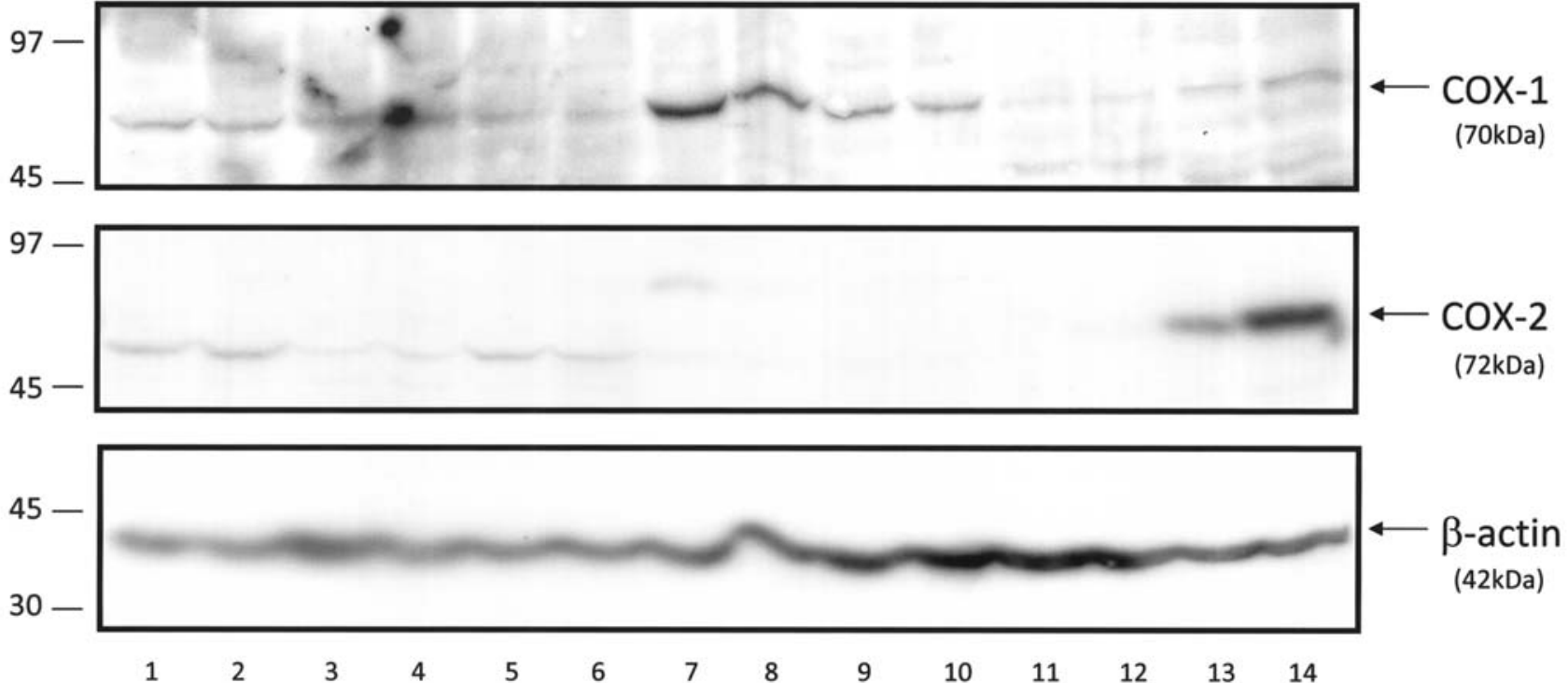

Figure 1. Expression of cyclooxygenase-1 (COX-1) and cyclooxygenase-2 (COX-2) in human hepatocellular carcinoma (HCC) cells. Expression levels of COX-1 and COX-2 in HCC cells were evaluated at mRNA and protein levels by reverse transcription-polymerase chain reaction (RT-PCR) and Western blot analysis, respectively. (A) RNA samples were obtained from 5 human HCC cells (HepG2, HLF, huH1, Huh7, and PLC/PRF/5) and cholangiocellular carcinoma cells (HuCCT-1) under serum-free [S(-)] and 10\% serum conditions [S(+)]. RT-PCR analysis was performed using the specific primers for COX-1 (top panel, 300 base pairs), COX-2 (middle panel, 232 base pairs), and B-actin (bottom panel, 318 base pairs) as described in Materials and methods. A549 cells unexposed (lane 14) and exposed to $500 \mu \mathrm{M}$ vanadate for $6 \mathrm{~h}$ (lane 15) served as positive controls for COX-2 mRNA. Lane 1 indicates size markers (SM) and lane 16 indicates an RNA-free sample, serving as a negative control (NC). bp, base pairs. (B) Total protein was harvested from the cells under similar conditions as described in (A). Western blot analysis was performed using the antibodies specific to COX-1 (top panel, $70 \mathrm{kDa}$ ) and COX-2 (middle panel, $72 \mathrm{kDa}$ ). Equal protein loading was confirmed by reprobing the membrane with the anti-ß-actin antibody (bottom panel). A549 cells untreated (lane 13) and treated with $500 \mu \mathrm{M}$ vanadate for $6 \mathrm{~h}$ (lane 14) served as positive controls for COX-2 protein.

the human HCC cells which we examined do not express COX-2.

Growth inhibitory effects of JTE-522 on HCC cells. Since there is a mounting body of evidence that selective COX-2 inhibitors exert anti-proliferative action to cancer cells through COX-2independent mechanisms (15), we decided to pursue whether JTE-522, a selective COX-2 inhibitor, could suppress the growth of HCC cells. When $100 \mu \mathrm{M}$ JTE-522 was added to HCC cells for $72 \mathrm{~h}$, the cellular growth was significantly 
A

control

$100 \mu \mathrm{M}$ JTE- $522 \times 72 \mathrm{~h}$

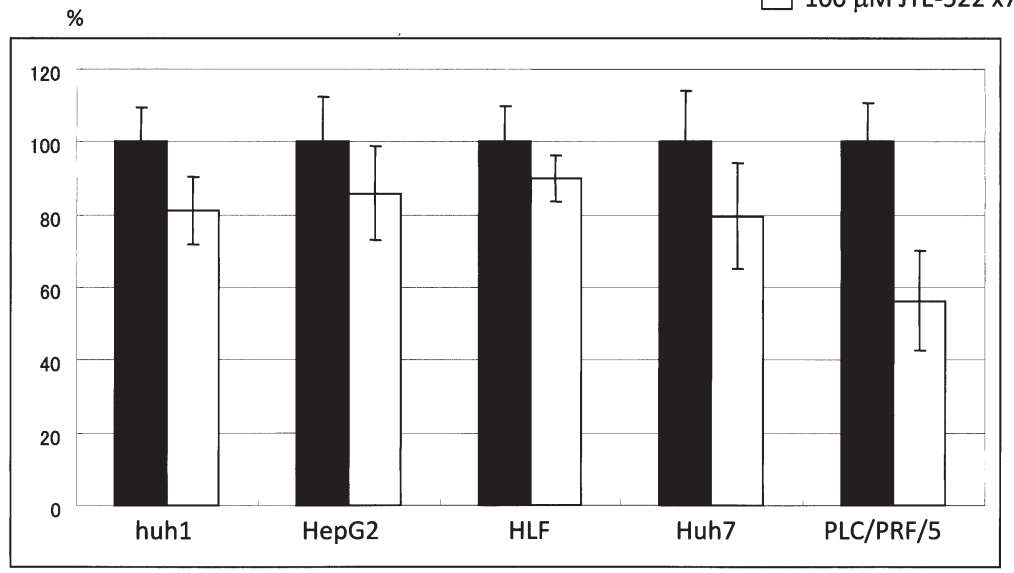

B
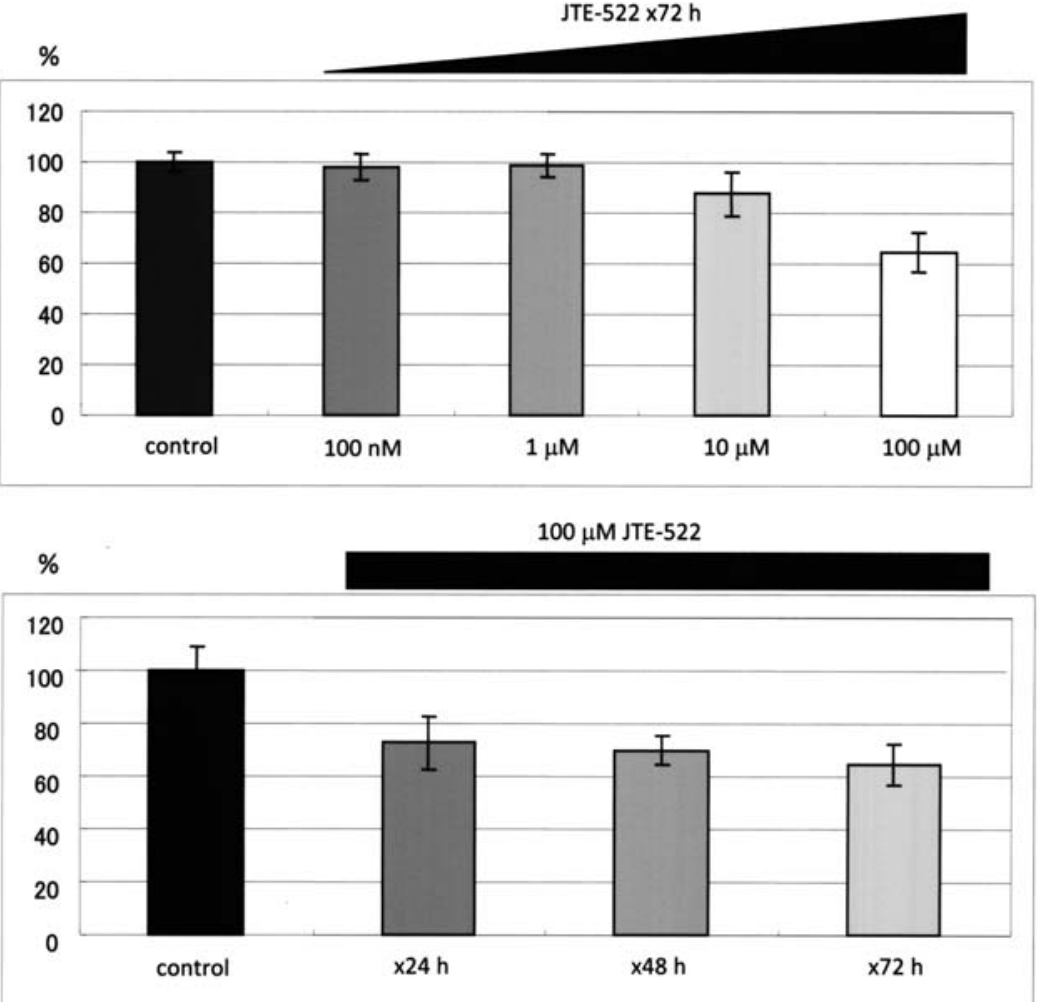

C

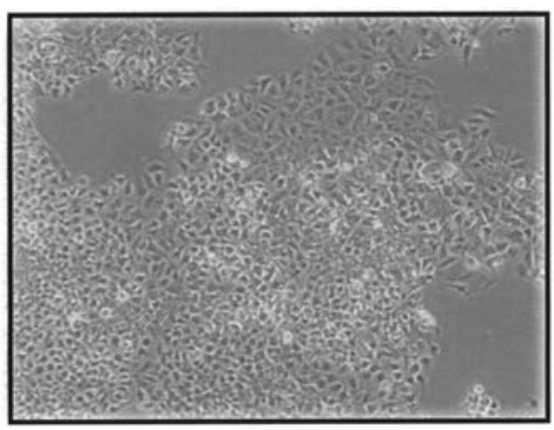

control

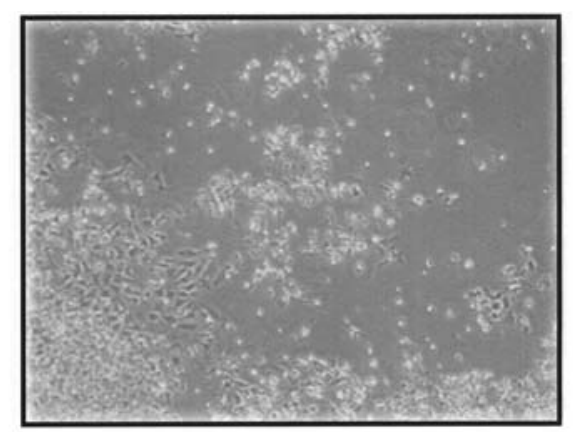

$100 \mu \mathrm{M}$ JTE-522 $\times 72 \mathrm{~h}$

Figure 2. Anti-proliferative effect of JTE-522 on HCC cells. HCC cells (HepG2, HLF, huH1, Huh7, and PLC/PRF/5) were treated with JTE-522, a selective COX-2 inhibitor, and the cellular growth was evaluated by MTT assays. The optical density (OD) 450 was expressed as a percentage of that of control cells containing $0.1 \%$ dimethyl sulfoxide (DMSO). (A) After HCC cells were treated with $100 \mu \mathrm{M}$ JTE-522 for $72 \mathrm{~h}$, the cellular growth was examined as above described. (B) After PLC/PEF/5 cells were treated with escalating doses of JTE-522 $(0.1,1,10$, and $100 \mu \mathrm{M})$ for $72 \mathrm{~h}$ (top panel), and treated with $100 \mu \mathrm{M}$ JTE-522 for 24, 48, and $72 \mathrm{~h}$ (bottom panel), the cellular growth was examined as described above. (C) After Huh7 cells were treated with $100 \mu \mathrm{M}$ JTE-522 for $72 \mathrm{~h}$, cells were observed under a light microscope (original magnification, $\mathrm{x} 40$ ). 

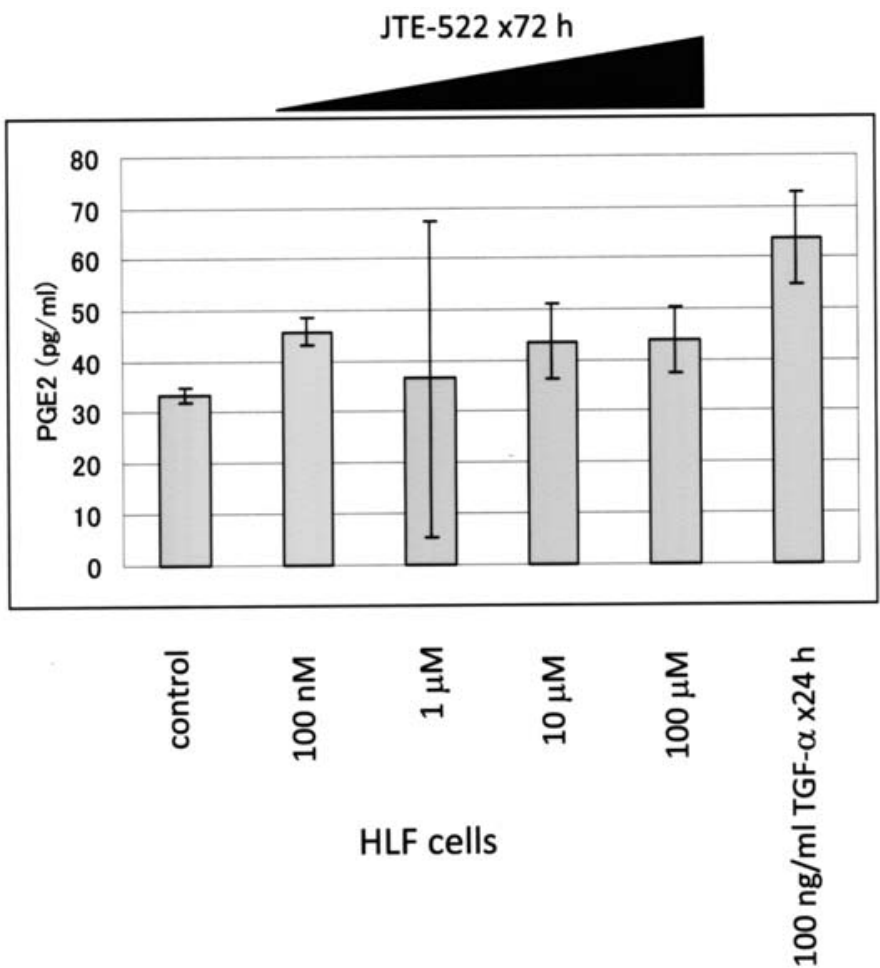
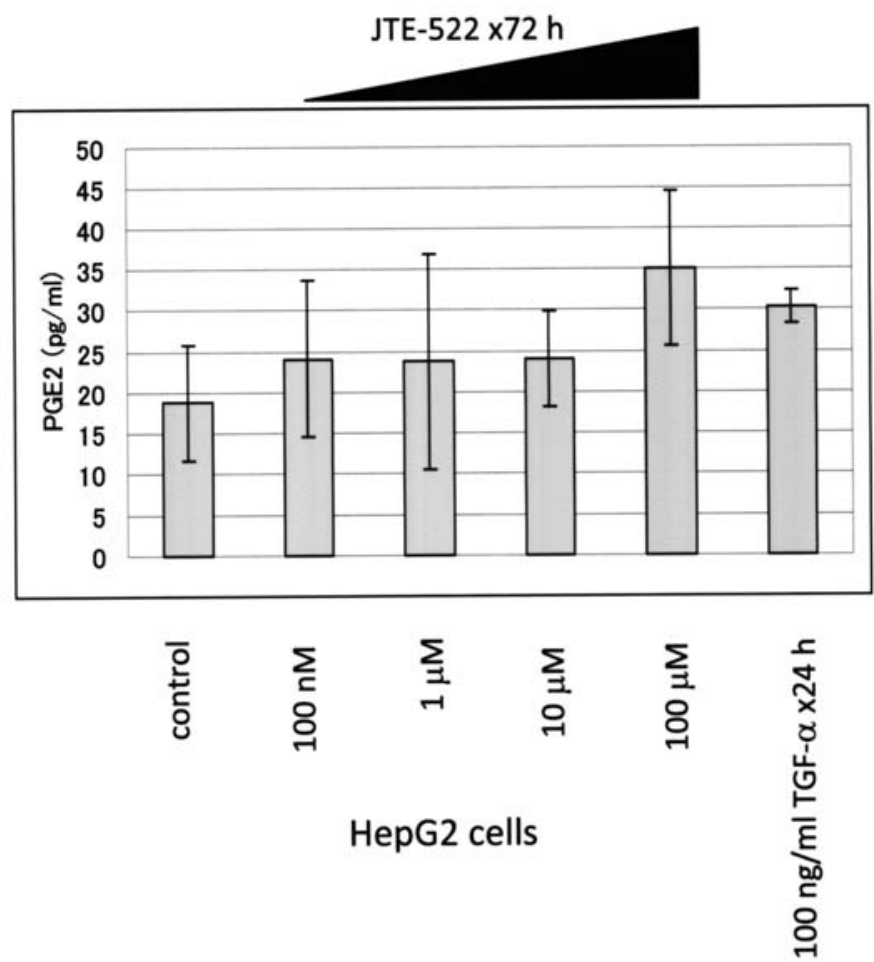

Figure 3. Prostaglandin E2 (PGE2) levels after JTE-522 treatment of HCC cells. PGE2 levels in culture medium were measured after HLF and HepG2 cells were treated with escalating doses of JTE-522 $(0.1,1,10$, and $100 \mu \mathrm{M})$ for $72 \mathrm{~h}$. The cells treated with $100 \mathrm{ng} / \mathrm{ml}$ of transforming growth factor- $\alpha$ (TGF- $\alpha$ ) for $24 \mathrm{~h}$ served as positive controls for increased PGE2 levels. The data were expressed as the mean \pm SD.

inhibited compared with control cells containing 0.1\% DMSO as solvent vehicle (Fig. 2A). When escalating doses of JTE-522 $(0.1,1,10$, and $100 \mu \mathrm{M})$ were administered to PLC/PEF/5 cells, the growth inhibition was observed when $>10 \mu \mathrm{M}$ JTE-522 was used (Fig. 2B, top panel), and it was observed mostly in a time-dependent manner (Fig. 2B, bottom panel). After the treatment, many cells were detached from the bottom of the culture dishes and were found floating in the medium (Fig. 2C).

PGE2 levels after JTE-522 treatment. The above data suggested that JTE-522 inhibited the growth of HCC cells in a COX-2-independent manner. To further confirm this finding, we measured PGE2 levels in medium after HCC cells were treated with JTE-522. When HLF and HepG2 cells were treated with $100 \mathrm{ng} / \mathrm{ml}$ of transforming growth factor- $\alpha$ (TGF- $\alpha$ ) for $24 \mathrm{~h}$, PGE2 levels were significantly increased; however, they were not significantly modified when treated with escalating doses of JTE-522 (Fig. 3).

Effects of JTE-522 on the cell cycle machinery and apoptosis. Next, we investigated the effects of JTE-522 on the cell cycle machinery in HCC cells. Flow cytometric analysis revealed that the cell cycle was blocked at the G1 phase after $72 \mathrm{~h}$ of the JTE-522 treatment in huH1 cells (Fig. 4A). Similar results were obtained in HLF cells (data not shown). The subG1 fraction, a hallmark of apoptosis, was not induced in either cell line after the treatment with JTE-522. The cell cycle arrest induced by JTE-522 appeared to be in part mediated by downregulation of cyclin E, although cyclin D1 and p27 were not significantly modulated by JTE-522 (Fig. 4B).
To further determine whether apoptosis is involved in the JTE-522-induced cell death, nuclear morphology was examined after HCC cells were treated with JTE-522. Nuclear condensation and fragmentation, indicative of apoptosis, were observed only in a few cells after treated with JTE-522 (Fig. 4C). In addition, activation of caspase-3 was not observed after huH1 and PLC/PRF/5 cells were treated with JTE-522 (Fig. 4D). These data suggest that apoptosis is not involved in the growth inhibition of HCC cells by JTE- 522 .

Possible role of PPAR- $\gamma$ in the cell death by JTE-522. Finally, we sought to clarify the signaling molecules involved in the anti-proliferative effect of JTE-522 independently of COX-2. We focused on analyzing the p38MAPK, JNK, and ERK1/2 signaling pathways, because these mitogen-activated protein kinases (MAPKs) have been demonstrated to play a pivotal role in the regulation of cell survival (16) and the action of nonsteroidal anti-inflammatory drugs (NSAIDs) (17). Western blot analysis with phosphorylation-specific antibodies revealed that these MAPKs were not significantly activated by JTE522 in our experimental conditions (Fig. 5A). Since it has been demonstrated that celecoxib, a selective COX-2 inhibitor, inhibited the growth of HCC cells via increased expression of PPAR- $\gamma$ (18), we evaluated the expression levels of PPAR- $\gamma$ at mRNA and protein levels after the JTE-522 treatment. PPAR $-\gamma$ protein was significantly activated after HepG 2 and $\mathrm{PLC} / \mathrm{PRF} / 5$ cells were treated with JTE-522 for $24 \mathrm{~h}$ (Fig. 5B), however, expression of PPAR- $\gamma$ at the mRNA level was not significantly modified by JTE-522 (Fig. 5C). Expression of PPAR $-\gamma$ either at mRNA or protein level was not significantly modulated in huH1 and HLF cells (Fig. 5B and C). 
A

JTE- $522 \times 72 \mathrm{~h}$

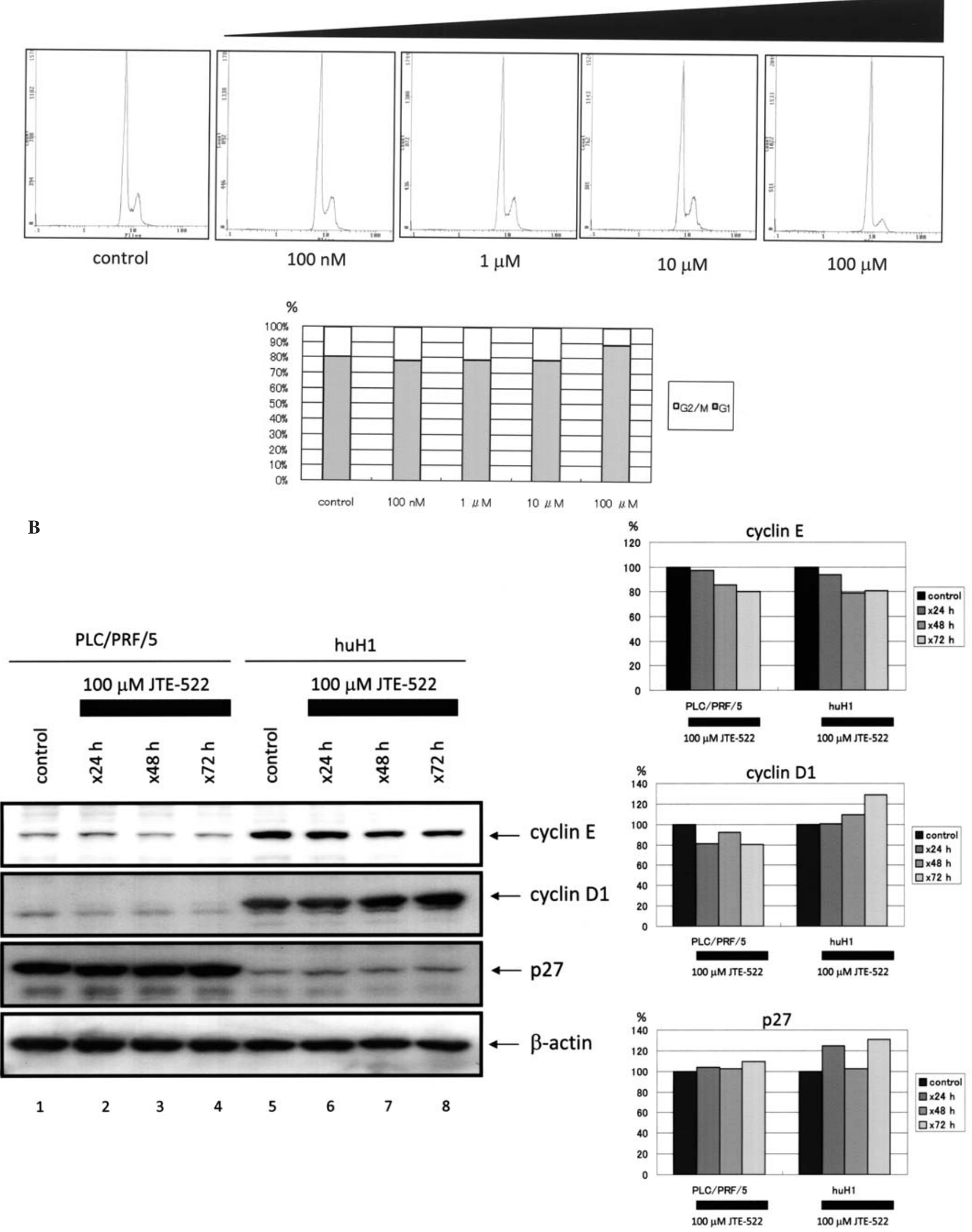

\section{Discussion}

Based on our findings that HCC cells did not express COX-2 mRNA and protein, and PGE2 levels in medium were not significantly modulated after $\mathrm{HCC}$ cells were treated with JTE-522, we concluded that JTE-522, a selective COX-2 inhibitor, suppressed the growth of HCC cells in a COX-2independent manner. Although we were unable to detect 
C
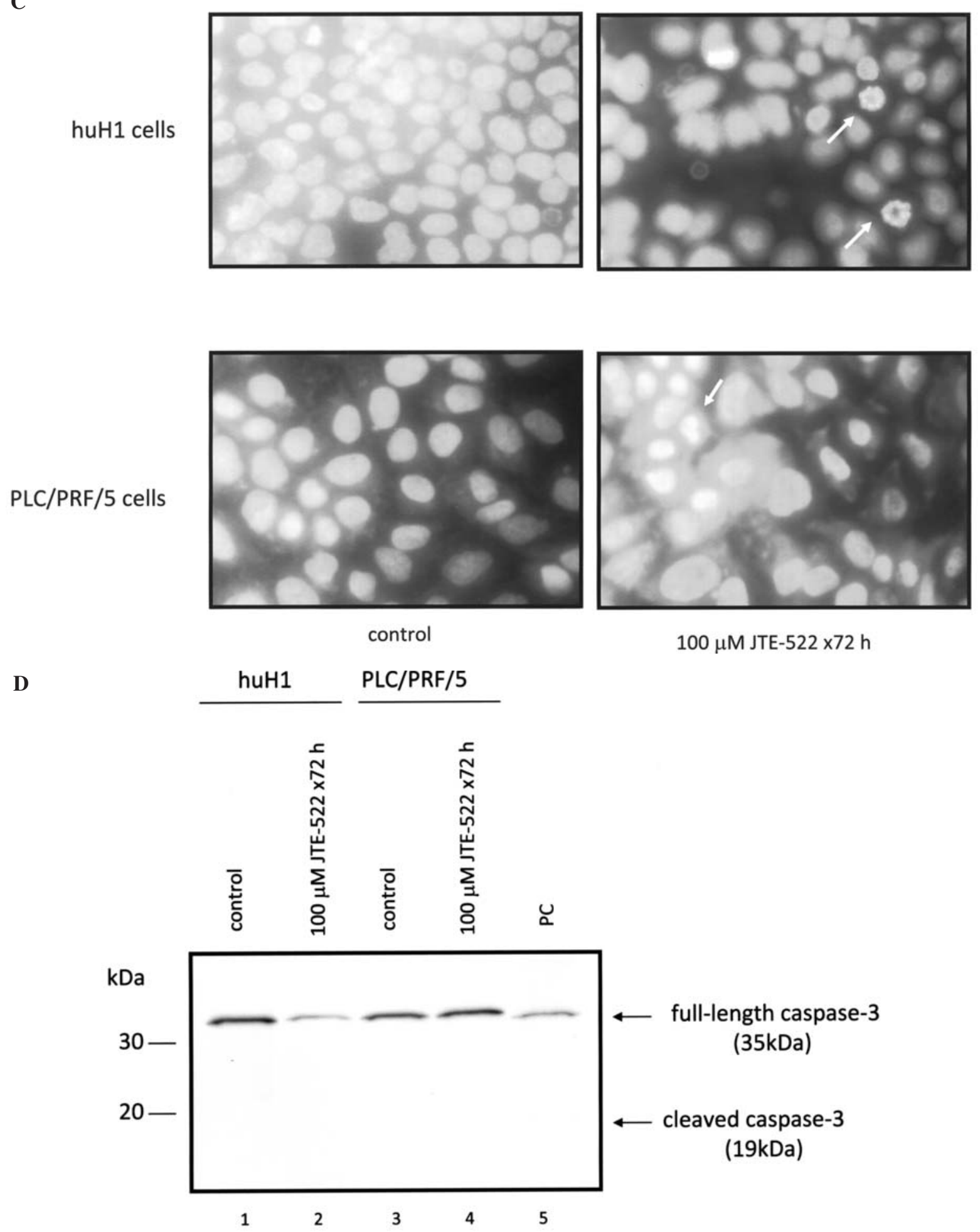

Figure 4. Effects of JTE-522 on the cell cycle machinery and apoptosis. (A) Flow cytometric analysis was performed after huH1 cells were treated with escalating doses of JTE-522 $(0.1,1,10$, and $100 \mu \mathrm{M})$ for $72 \mathrm{~h}$. (B) Total protein samples were extracted after PLC/PRF/5 and huH1 cells were treated with $100 \mu \mathrm{M}$ JTE-522 for 24, 48, and $72 \mathrm{~h}$, and Western blot analysis was conducted by probing with antibodies against cyclin E, cyclin D1, and p27. Equal protein loading was confirmed by reprobing the membrane with the anti-ß-actin antibody (bottom panel). (C) Nuclear morphology was examined by Hoechst 33258 staining after huH1 and PLC/PRF/5 cells were treated with $100 \mu \mathrm{M} \mathrm{JTE}-522$ for $72 \mathrm{~h}$. The cells were observed under a fluorescent microscopy. Arrows indicate a few apoptotic cells (original magnification, $\mathrm{x} 400$ ). (D) After huH1 and PLC/PRF/5 cells were treated with $100 \mu \mathrm{M}$ JTE-522 for $72 \mathrm{~h}$, activation of caspase-3 was evaluated by Western blot analysis utilizing the anti-caspase-3 antibody detecting both full-length (35 kDa) and activated (19 kDa) caspase-3. Lane 5 indicates a positive control (PC) for activated caspase-3.

COX-2 expression in HCC cells, contradictory data exist as to the expression of COX-2 in HCC cells. For instance, in HepG2 cells, COX-2 was expressed in some reports $(5,7)$, but was negative in others $(6,8)$ in concert with our data. Since COX-2 expression is regulated by a variety of signaling molecules including polypeptide growth factors, glycogen 
A

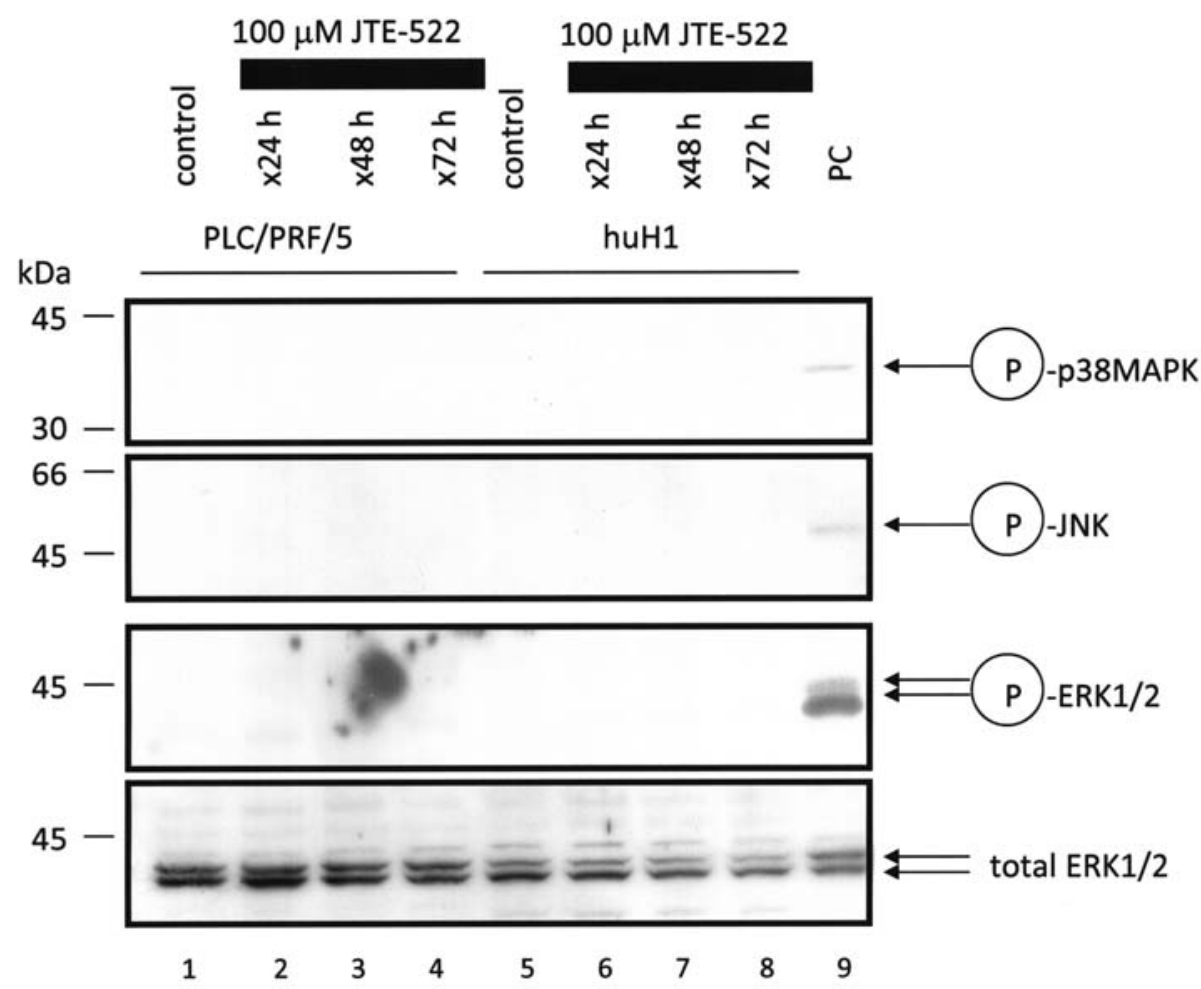

B
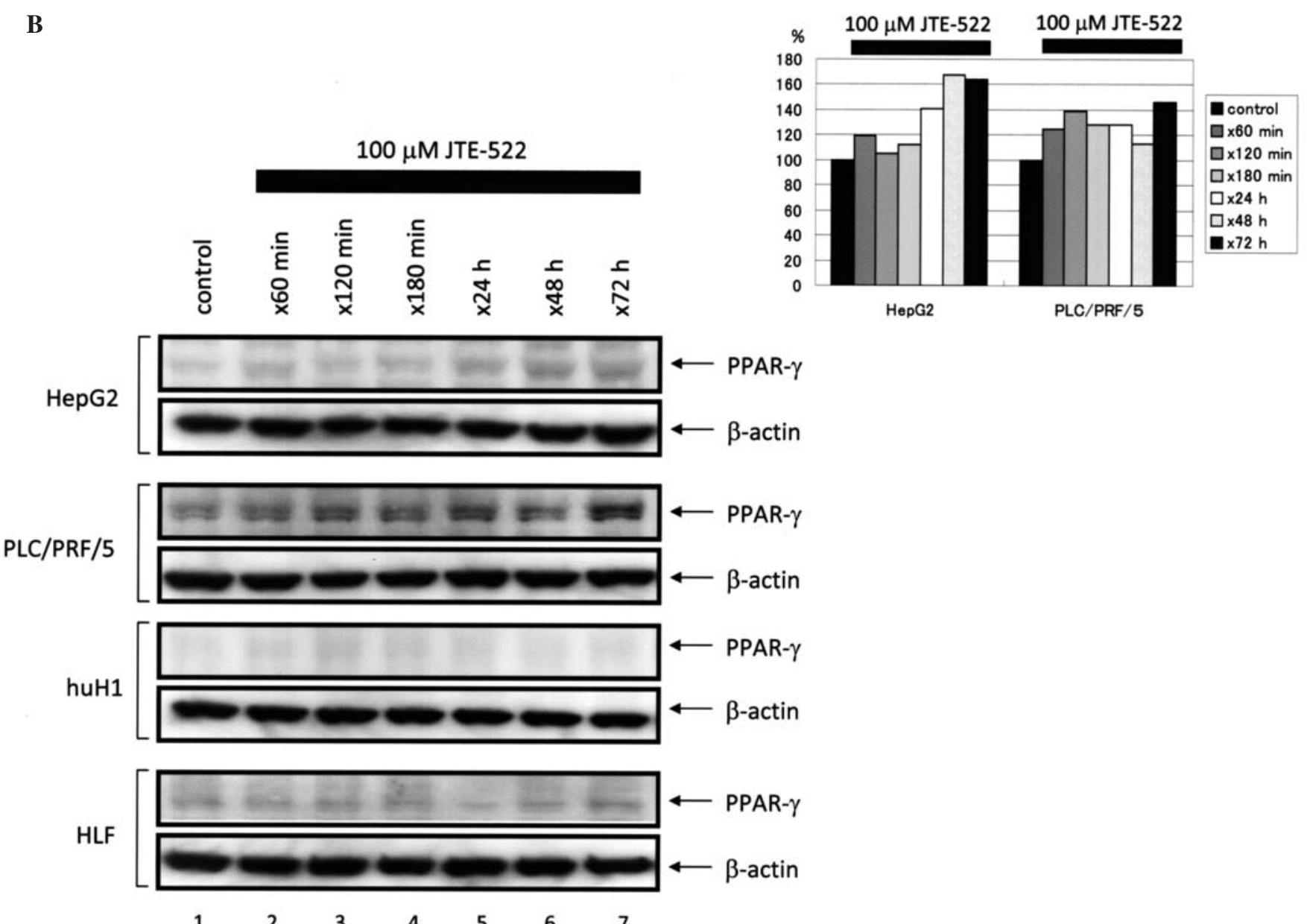

synthase kinase (GSK)-3ß, Wnt, and Ras $(19,20)$, the above controversial results may originate from the different experimental conditions which could affect these signaling molecules.
The growth inhibitory effect of selective COX-2 inhibitors has been demonstrated in a variety of cancer cells including HCC cells (5-8). However, it is controversial whether the growth inhibition is mediated through the pathways dependent 


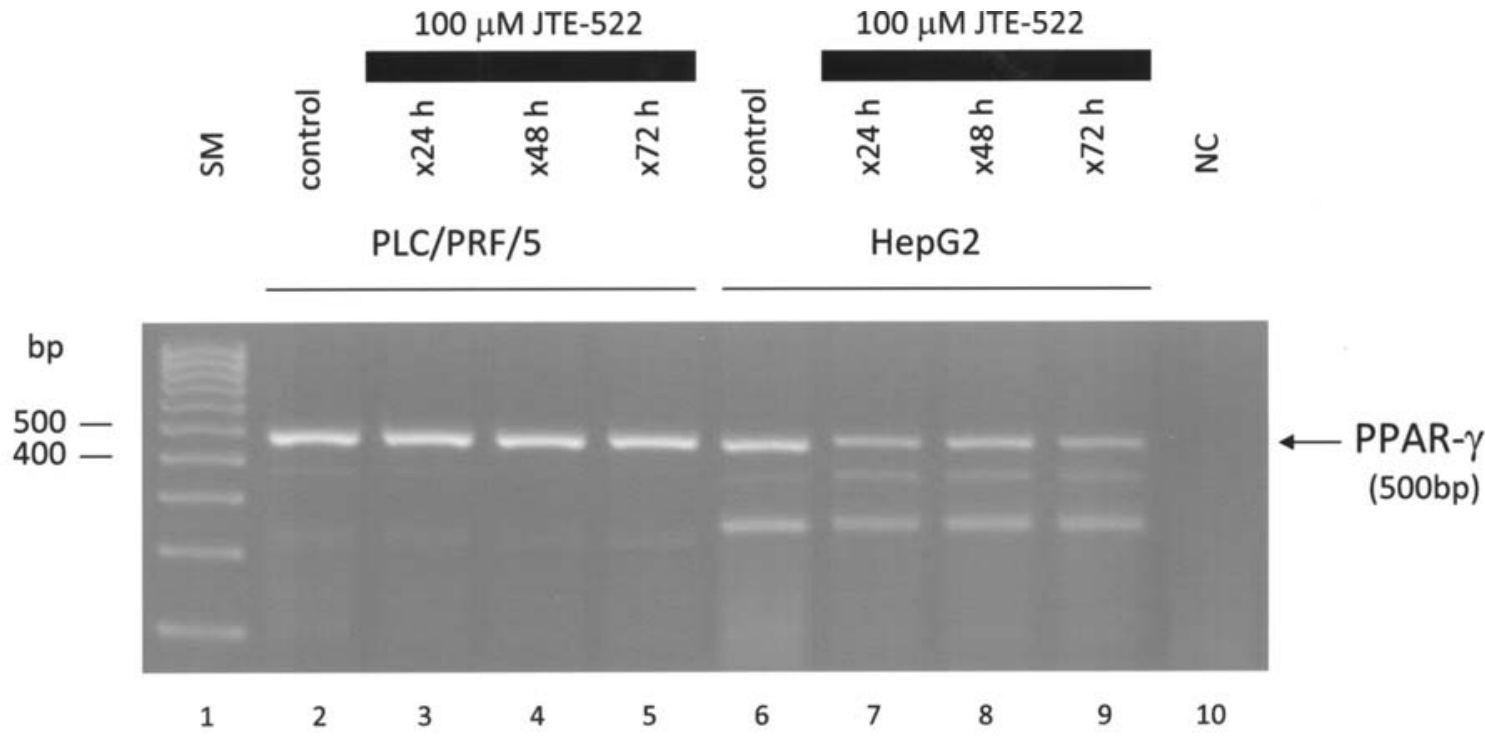

Figure 5. Identification of signaling molecules involved in the anti-proliferative effect of JTE-522. (A) After PLC/PRF/5 and huH1 cells were treated with $100 \mu \mathrm{M}$ JTE-522 for 24, 48, and $72 \mathrm{~h}$, activations of p38MAPK, c-Jun N-terminal kinase (JNK), and ERK (extracellular signal-regulated kinase) 1/2 were evaluated by Western blot analysis utilizing phosphorylation-specific antibody for each molecule. Lane 9 indicates a positive control (PC) for each molecule. The bottom panel demonstrates an equal protein loading by reprobing the membrane with the phosphorylation-independent anti-ERK1/2 antibody. (B) After HepG2, PLC/PRF/5, huH1, and HLF cells were treated with $100 \mu \mathrm{M}$ JTE-522 for 60, 120, and 180 min, and 24, 48, and 72 h, expression levels of peroxisome proliferator-activated receptor (PPAR)- $\gamma$ were evaluated by Western blot analysis. Equal protein loading was confirmed by reprobing the membranes with the anti- $\beta$-actin antibody. (C) Expression levels of PPAR- $\gamma$ were evaluated by semi-quantitative RT-PCR analysis with PPAR- $\gamma$-specific primers (500 base pairs) as described in Materials and methods. RNA samples were collected from PLC/PRF/5 and HepG2 cells treated with $100 \mu \mathrm{M}$ JTE-522 for 24,48 , and 72 h. Lane 1 indicates size markers (SM) and lane 10 indicates an RNA-free sample, serving as a negative control (NC). bp, base pairs.

on or independent of COX-2. Recent observations have identified a variety of molecules as the targets for $\mathrm{COX}-2$ inhibitors, including AKT, ERK1/2, nuclear factor-кB (NF-кB), and PPAR- $\gamma$. We did not observe a significant modulation of the NF-кB pathway when HCC cells were challenged with JTE-522 (data not shown). Our data support the idea that selective COX-2 inhibitors exert anti-proliferative action in a COX-2-independent manner, and suggest that the action may be mediated by PPAR- $\gamma$. PPAR- $\gamma$ is a member of the nuclear receptor superfamily which mediates transcriptional regulation of genes involved in lipid metabolism, inflammation, cell differentiation, and survival (22). Previous observations that PPAR $-\gamma$ ligands inhibited the growth of HCC cells in vitro and in vivo (23), and that there is a cross-talk between PPARs and COX-2 signaling pathways in HCC cells $(23,24)$ support the idea. It is unclear why upregulation of PPAR- $\gamma$ was observed only in a subset of HCC cells, and was observed at protein level alone in our study. We speculate that posttranscriptional regulation of PPAR- $\gamma$ may be involved, because paradoxical expression pattern of PPARs between mRNA and protein levels has been demonstrated in the literature $(25,26)$. To substantiate our finding that PPAR- $\gamma$ may be a downstream target of a selective COX-2 inhibitor in HCC cells, further investigations, including a knock down of PPAR- $\gamma$ gene, will be necessary.

Most of the previous reports demonstrated an involvement of apoptosis in the anti-proliferative effect of a selective COX-2 inhibitor (5-8). However, cell cycle arrest by a selective COX-2 inhibitor without induction of apoptosis has also been reported in HCC cells (11). In addition, there is a previous report demonstrating that expression levels of COX-2 in cells and serum condition in medium influence the induction of apoptosis by NS398, a selective COX-2 inhibitor, in lung cancer cells (27). When considering these previous reports, it is not surprising that JTE-522 inhibited the growth of HCC cells without induction of apoptosis.

In summary, our present study demonstrated that a selective COX-2 inhibitor JTE-522 inhibited the proliferation of HCC cells in a COX-2-independent manner, and that the growth inhibition was in part mediated by the cell cycle arrest and the upregulation of PPAR- $\gamma$. Our findings will shed light on the possibility that JTE-522 can be applied for the treatment of patients with HCC.

\section{Acknowledgements}

We would like to thank Japan Tobacco, Inc. (Tokyo, Japan) for kindly donating JTE-522 and for their technical assistance.

\section{References}

1. Bosch FX, Ribes $\mathrm{J}$ and Borras $\mathrm{J}$ : Epidemiology of primary liver cancer. Semin Liver Dis 19: 271-285, 1999.

2. Okuda H: Hepatocellular carcinoma development in cirrhosis. Best Pract Res Clin Gastroenterol 21: 161-173, 2007.

3. Shiota G, Okubo M, Noumi T, et al: Cyclooxygenase-2 expression in hepatocellular carcinoma. Hepatogastroenterology 46: 407-412, 1999.

4. Leng J, Han C, Demetris AJ, Michalopoulos GK and Wu T: Cyclooxygenase-2 promotes hepatocellular carcinoma cell growth through Akt activation: evidence for Akt inhibition in celecoxib-induced apoptosis. Hepatology 38: 756-768, 2003.

5. Kern MA, Haugg AM, Koch AF, et al: Cyclooxygenase-2 inhibition induces apoptosis signaling via death receptors and mitochondria in hepatocellular carcinoma. Cancer Res 66: 7059-7066, 2006. 
6. Fodera D, D'Alessandro N, Cusimano A, et al: Induction of apoptosis and inhibition of cell growth in human hepatocellular carcinoma cells by COX-2 inhibitors. Ann NY Acad Sci 1028: 440-449, 2004.

7. Li J, Chen X, Dong X, Xu Z, Jiang H and Sun X: Specific COX-2 inhibitor, meloxicam, suppresses proliferation and induces apoptosis in human HepG2 hepatocellular carcinoma cells. J Gastroenterol Hepatol 21: 1814-1820, 2006.

8. Rahman MA, Dhar DK, Masunaga R, Yamanoi A, Kohno H and Nagasue N: Sulindac and exisulind exhibit a significant antiproliferative effect and induce apoptosis in human hepatocellular carcinoma cell lines. Cancer Res 60: 2085-2089, 2006.

9. Marquez-Rosado L, Trejo-Solis MC, Garcia-Cuellar CM and Villa-Trevino S: Celecoxib, a cyclooxygenase-2 inhibitor, prevents induction of liver preneoplastic lesions in rats. J Hepatol 43: 653-660, 2005.

10. Cervello M and Montalto G: Cyclooxygenases in hepatocellular carcinoma. World J Gastroenterol 12: 5113-5121, 2006.

11. Cheng J, Imanishi H, Amuro Y and Hada T: NS-398, a selective cyclooxygenase 2 inhibitor, inhibited cell growth and induced cell cycle arrest in human hepatocellular carcinoma cell lines. Int J Cancer 99: 755-761, 2002.

12. Matsumoto K, Okano J, Nagahara T and Murawaki Y: Apoptosis of liver cancer cells by vitamin K2 and enhancement by MEK inhibition. Int J Oncol 29: 1501-1518, 2006.

13. Tammali R, Ramana KV, Singhal SS, Awasthi S and Srivastava SK: Aldose reductase regulates growth factorinduced cyclooxygenase-2 expression and prostaglandin E2 production in human colon cancer cells. Cancer Res 66: 9705-9713, 2006.

14. Chien PS, Mak OT and Huang HJ: Induction of COX-2 protein expression by vanadate in A549 human lung carcinoma cell line through EGF receptor and p38 MAPK-mediated pathway. Biochem Biophys Res Commun 339: 562-568, 2006.

15. Grosch S, Maier TJ, Schiffmann S and Geisslinger G: Cyclooxygenase-2 (COX-2)-independent anticarcinogenic effects of selective COX-2 inhibitors. J Natl Cancer Inst 98: 736-747, 2006.

16. Javelaud D and Mauviel A: Crosstalk mechanisms between the mitogen-activated protein kinase pathways and Smad signaling downstream of TGF-beta: implications for carcinogenesis. Oncogene 24: 5742-5750, 2005.
17. Sun Y and Sinicrope FA: Selective inhibitors of MEK1/ ERK44/42 and p38 mitogen-activated protein kinases potentiate apoptosis induction by sulindac sulfide in human colon carcinoma cells. Mol Cancer Ther 4: 51-59, 2005

18. Cui W, Yu CH and Hu KQ: In vitro and in vivo effects and mechanisms of celecoxib-induced growth inhibition of human hepatocellular carcinoma cells. Clin Cancer Res 11: 8213-8221, 2005.

19. Araki Y, Okamura S, Hussain SP, et al: Regulation of cyclooxygenase- 2 expression by the Wnt and Ras pathways. Cancer Res 63: 728-734, 2003.

20. Thiel A, Heinonen M, Rintahaka J, et al: Expression of cyclooxygenase- 2 is regulated by glycogen synthase kinase- 3 beta in gastric cancer cells. J Biol Chem 281: 4564-4569, 2006.

21. Pang RP, Zhou JG, Zeng ZR, et al: Celecoxib induces apoptosis in COX-2 deficient human gastric cancer cells through Akt/ GSK3beta/NAG-1 pathway. Cancer Lett 251: 268-277, 2007.

22. Koeffler HP: Peroxisome proliferator-activated receptor gamma and cancers. Clin Cancer Res 9: 1-9, 2003.

23. Yu J, Qiao L, Zimmermann L, et al: Troglitazone inhibits tumor growth in hepatocellular carcinoma in vitro and in vivo. Hepatology 43: 134-143, 2006.

24. Xu L, Han C, Lim K and Wu T: Cross-talk between peroxisome proliferator-activated receptor delta and cytosolic phospholipase $\mathrm{A}(2)$ alpha/cyclooxygenase-2/prostaglandin E(2) signaling pathways in human hepatocellular carcinoma cells. Cancer Res 66: $11859-11868,2006$.

25. McClure TD, Young ME, Taegtmeyer $\mathrm{H}$, et al: Thyroid hormone interacts with PPARalpha and PGC-1 during mitochondrial maturation in sheep heart. Am J Physiol Heart Circ Physiol 289: $\mathrm{H} 2258-\mathrm{H} 2264,2005$.

26. Sterchele PF, Sun H, Peterson RE and Vanden Heuvel JP: Regulation of peroxisome proliferator-activated receptor-alpha mRNA in rat liver. Arch Biochem Biophys 326: 281-289, 1996.

27. Chang HC and Weng CF: Cyclooxygenase-2 level and culture conditions influence NS398-induced apoptosis and caspase activation in lung cancer cells. Oncol Rep 8: 1321-1325, 2001 